\title{
OS DESAFIOS DO DESENHO DIDÁTICO DA EDUCAÇÃO ONLINE EM TEMPOS DE CIBERCULTURA
}

Alice Maria Figueira Reis da Costa | alicemaria.costa@yahoo.com.br Pedagoga pela UERJ, pós-graduada latu sensu em Psicopedagogia pela UERJ e em Educação Especial pela UNIRIO. Exerce tutoria presencial pela Fundação Cecierj/UERJ e tutoria a distância pela Fiocruz.

Felipe da Silva Ponte de Carvalho | felipesilvaponte@yahoo.com.br Pedagogo pelo Centro Universitário da Cidade do Rio de Janeiro e atua como tutor a distância pela Fundação Cecierj .

\section{Resumo}

O desenho didático e o exercício da tutoria sob a perspectiva da Educação Online assumem um papel conflitante diante das dicotomias em relação à Educação a Distância (EaD) online tradicional presente no curso de Licenciatura em Pedagogia da UERJ/Fundação Cecierj. A essas dicotomias atribuímos as peculiaridades epistemológicas que perpassam as questões da metodologia, da docência e do desenho didático realizado na disciplina Informática na Educação. Neste trabalho, optamos por narrar as práticas pedagógicas de professores pesquisadores, tutores presenciais em espaçotempos, onde se vive o fenômeno da cibercultura relativo aos polos de Belford Roxo e Angra dos Reis. Nesse sentido, encontramos na metodologia da pesquisa-ação as orientações necessárias para alavancar a reflexão metodológica e didática deste curso de formação de professores, enquanto alteramos a nossa própria práxis. Para tal, investigamos a interface digital da plataforma CEDERJ, assim como outras, para que pudéssemos entender melhor as possibilidades da Educação Online na contemporaneidade dos usos de softwares sociais e da convergência das mídias digitais. Como resultado de nossa docência online, colaboramos na tensão epistemológica existente entre o conceito tradicional de EaD Online e de Educação Online. Este último conceito é permeado pelos estudos da Antropologia e Sociologia que compreendem e refletem o desenvolvimento da aprendizagem humana em interatividade nas/com as hipermídias.

\section{Palavras-chave}

EaD Online. Educação Online. Desenho didático. Docência online. 


\section{The challenges of teaching design of online education in times of cyberculture}

\section{Abstract}

The instructional design and practice of mentoring from the perspective of Online Education play a role in the face of conflicting dichotomies in relation to distance learning (ODL) present in traditional online course Pedagogy UERJ / Foundation CECIERJ . The dichotomies attach to these epistemological peculiarities that underlie the issues of methodology, teaching and didactic design made in the discipline Computers in Education. In this work we chose to narrate the pedagogical practices of teachers tutors researchers face in spacetimes, where the phenomenon of cyberspace for the Centers of Belford Roxo and Angra dos Reis. In this sense is found in live action research methodology, the need to leverage this methodological and theoretical reflection of this ongoing teacher training guidelines as changed our own praxis. To this end, we investigated the digital interface CEDERJ platform, as well as other so that we could better understand the possibilities of Online Education in contemporary uses of social software and the convergence of digital media. As a result of our online faculty collaborate on epistemological tension between the traditional concept of Online Distance Learning and Online Education. This latter concept permeated by the studies of anthropology and sociology who understand and reflect the development of human interactivity in learning / with hypermedia.

\section{Keywords}

Distance Learning Online. Online Education. Didactic design. Teaching Online.

\section{Introdução}

Atualmente, a Fundação Centro de Ciências e Educação Superior a Distância do Estado do Rio de Janeiro (Cecierj) / Consórcio Cederj, pessoa jurídica de direito público, vinculada à Secretaria de Estado de Ciência e Tecnologia, vinculada ao Ministério da Educação (MEC) e integrada à administração estadual indireta, visa cooperar com o compromisso assumido no Plano Nacional de Educação (PNE 2001-2010) no que tange a expressivo déficit educativo $e$ às desigualdades regionais, segundo dados levantados por pesquisas quantitativas realizadas pela Associação Brasileira de Educação a Distância (ABED) no Censo EaD. $B R 1^{1}$ (2009). Nele podemos verificar um quantitativo de 2.648.031 alunos que estudaram na modalidade de Educação a Distância (EaD) no ano 2008 no Brasil, distribuídos em instituições credenciadas, cursos livres e educação corporativa, conforme a Tabela 1.

Ainda em pesquisas quantitativas realizadas pelo Instituto Nacional de Estudos e Pesquisas Educacionais Anísio Teixeira (Inep) e Instituto Brasileiro de Geografia e Estatística (IBGE), de acordo com o senso realizado no ano 2010 no Brasil, divulgado pelo mais recente objeto de aprendizagem do IBGE chamado Paisesat ${ }^{2}$ , constatamos que nos cursos de graduação a distância no Brasil tivemos 838.125 alunos matriculados no ano 2009 , o que representava aproximadamente $0,43 \%$ da população brasileira, estimada em um total de 190.732.694 habitantes. No que concerne ao Estado do Rio de Janeiro, havia 45.721 alunos matriculados nos curso de graduação a distância, com 19.600 alunos nas unidades públicas de ensino e 5.032 nas unidades estaduais de graduação a distância, alcançando 485 alunos concluintes dos seus respectivos cursos.

Neste trabalho nos limitamos a considerar a tutoria presencial realizada em dois polos: no município de Angra dos Reis-RJ e no município de Belford Roxo-RJ, com oferta de cursos de graduação em oito e três áreas do conhecimento respectivamente, na modalidade de educação a distância. A partir das vivências na tutoria presencial do curso de Licenciatura em $\mathrm{Pe}$ dagogia da Universidade do Estado do Rio de Janeiro (UERJ), fica mais verossímil a intenção deste artigo, de refletir sobre o aporte teórico-metodológico da práxis (prática-teoria-prática) da Educação Online.

1 http://www.abed.org.br/censoead/CensoEaDbr0809_portugues.pdf

2 Dados disponíveis no site: http://www.ibge.gov.br/paisesat/main.php 
Tabela 1: Brasileiros que estudaram com Educação a Distância (EaD) (2008). Censo EaD.br, 2009 (ABED), disponível em: http://www.abed.org.br/censoead/CensoEaDbr0809_portugues.pdf

\begin{tabular}{l|l|l}
$\begin{array}{c}\text { Tipo de levantamento / } \\
\text { Type of survey }\end{array}$ & $\begin{array}{c}\text { Número de alunos no país / } \\
\text { Number of students in the country }\end{array}$ & \multicolumn{1}{c}{ Descrição / Description } \\
$\begin{array}{l}\text { Instituições credenciadas / Ac- } \\
\text { credited institutions }\end{array}$ & 1.075 .272 & $\begin{array}{l}\text { Alunos de instituições credenciadas para ministrar EAD pelo Sistema de } \\
\text { Educação (Conselho Nacional de Educação e Conselhos Estaduais de } \\
\text { Educaça) / Students of institutions accredited to conduct EAD by the } \\
\text { Education System (National Council for Education and State Councils } \\
\text { for Education) }\end{array}$ \\
\hline $\begin{array}{l}\text { Cursos livres / Non-formal } \\
\text { courses }\end{array}$ & $\begin{array}{l}\text { Alunos de 42 instituições que oferecem cursos livres a distância (exem- } \\
\text { plos: Senac, Senai, Fundação Bradesco, Alumni, Portal Educação etc.) / } \\
\text { Students from 42 institutions offering non- formal distance courses (for } \\
\text { instance: Senac, Senai, Fundação Bradesco, Alumni, Portal Educação, } \\
\text { etc.) }\end{array}$ \\
\hline $\begin{array}{l}\text { Educação corporativa / Cor- } \\
\text { porative learning }\end{array}$ & $\begin{array}{l}\text { Alunos de 32 empresas ou instituições que ministram cursos a distância } \\
\text { para seus próprios funcionários ou colaboradores (exemplos: Itaú/Uni- } \\
\text { banco, Petrobrás, Vale, Xerox, etc) / Students from 32 companies or ins- } \\
\text { tutions conducting distance courses to their own employees (for instance: } \\
\text { Itaú/Unibanco, Petrobrás, Vale, Xerox, etc.)) }\end{array}$ \\
\hline Total & 498.653 & $\mathbf{2 . 6 4 8 . 0 3 1}$
\end{tabular}

A propósito, "no processo de universalização e democratização do ensino, especialmente no Brasil, onde os déficits educativos e as desigualdades regionais são tão elevados, os desafios educacionais existentes podem ter, na Educação a Distância, um meio auxiliar de indiscutível eficácia”, conforme está no diagnóstico apresentado no capítulo 6 inciso 6.1 do PNE 2001-2010. E, para este, ao introduzir novas concepções de tempo e de espaço na Educação, a Educação a Distância tem função estratégica: contribuir para o surgimento de mudanças significativas na instituição escolar e influir nas decisões a serem tomadas pelos dirigentes políticos e pela sociedade civil na definição das prioridades educacionais.

É preciso salientar que os programas educativos têm a função de desempenhar papel inestimável no desenvolvimento cultural da população, considerando a necessidade de mediação tecnológica para impulsionar a flexibilidade do processo educativo por meio das tecnologias e de pesquisas regionais e nacionais que devem ser desenvolvidas para a elaboração de técnicas que deem conta de um design educacional (MATTAR, 2011) peculiar da docência online.

Esse design educacional compreende o design instrucional, o design didático e o design de games, em que o professor tutor deve ser corresponsável por todo o processo de ensinoaprendizagem. Adiante veremos como ocorre o sistema de tutoria pela Universidade do Estado do Rio de Janeiro /Fundação Cecierj, em especial na disciplina Informática Educativa.

O sistema de tutoria presencial está administrativa e pedagogicamente subordinado ao professor tutor coordenador de área; este último atende a todos os polos da Fundação Cecierj em que seu curso/disciplina estiver presente. O organograma da Figura 1 apresenta a estrutura administrativa vigente na Fundação Cecierj. 


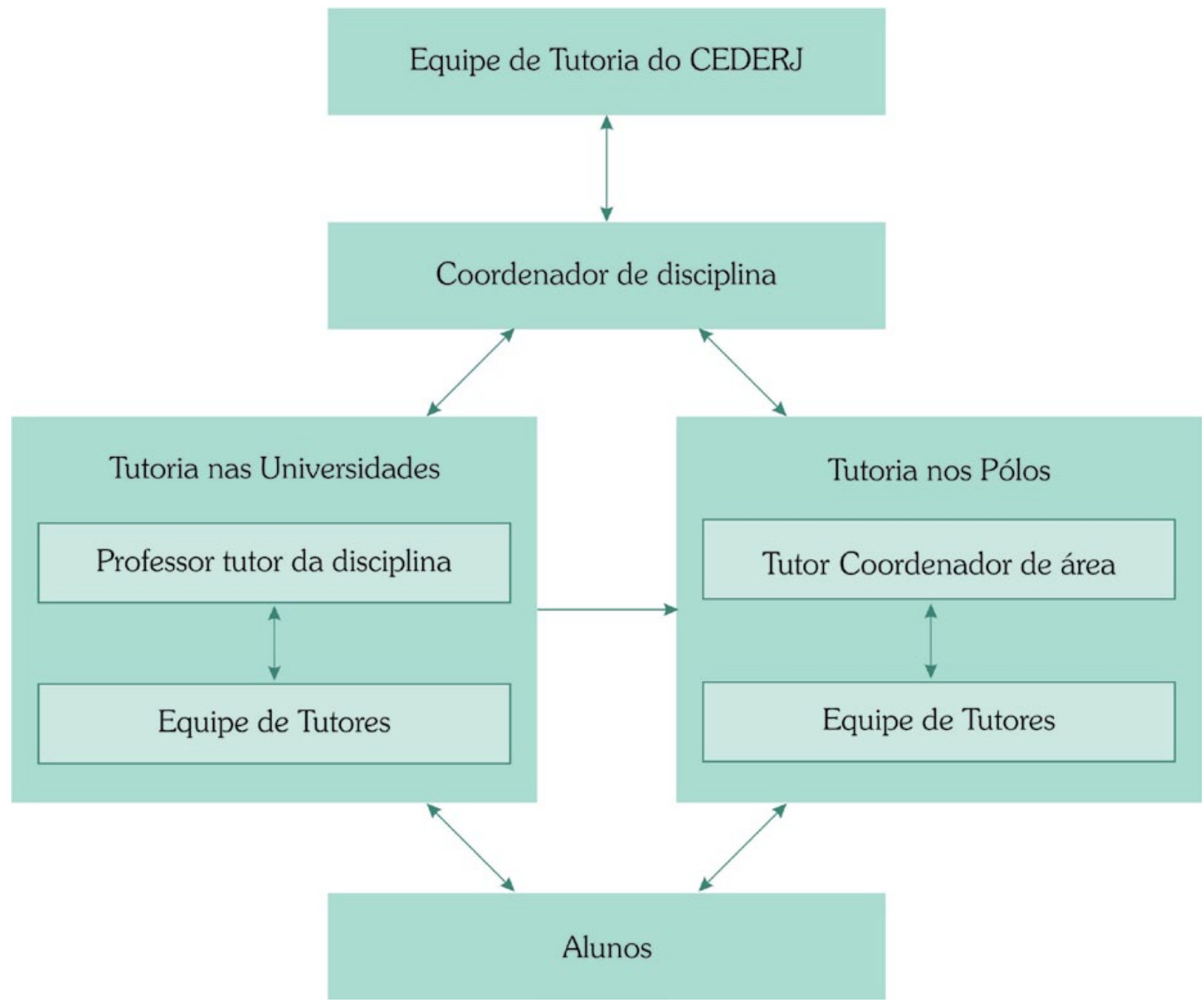

Figura 1: Relacionamento entre as instâncias acadêmicas do Consórcio Cederj (LIMA, 2002).

Essa tutoria presencial era exercida nos polos de estudos: o trabalho consistia em tirar dúvidas dos alunos em relação aos conteúdos das aulas distribuídas em formato pdf e/ou materiais didáticos impressos ou na mídia CD/DVD e na correção das avaliações a distância (ADs); mediar as ocorrências no ambiente virtual de aprendizagem (AVA), plataforma Cederj, na Sala de Tutoria, e-mails, nos fóruns e/ou nas mensagens instantâneas (MIs).

A tutoria a distância e a tutoria presencial realizaram um trabalho colaborativo, sistematizado pelas mediações online, atendimento ao telefone 0800 e a correção das avaliações presenciais (APs). No polo tínhamos o tutor coordenador de área responsável pela logística da tutoria presencial organizando horários, recebimento de planilha de notas, vistas de provas etc.

\section{Curso de Pedagogia UERJ/Cederj: co- nhecendo e tecendo o cenário sociotécnico}

$\mathrm{Na}$ contemporaneidade do século XXI presenciamos um movimento intenso de digitalização da informação; em sequência, outros usos foram construídos como maior acesso aos sistemas informatizados, por exemplo, a automatização das operações bancárias e do envio do imposto de renda, as câmeras fotográficas mudaram para a tecnologia digital, as telas de LCD, LED, notebooks, netbooks tornaram-se mais comuns e gradativamente estas e outras tecnologias digitais foram chegando às camadas mais populares.

Consequentemente, as relações interpessoais foram se alterando, sendo reinventada a propor- 
ção da interatividade do homem com as hipermídias (multimídias, multilinguagens online), os laços sociais foram construídos com maior rapidez, as informações sofreram e sofrem constantes atualizações, cresce o uso da correspondência eletrônica (e-mail), os jovens começaram a compartilhar jogos em rede, arquivos pessoais, editar textos em mídias digitais que facilitam a reescrita, grupos de pessoas começaram se organizar para tratar de determinados assuntos online, filmar e editar seus eventos, editar seus próprios filmes, álbum de fotografias, softwares/sites sociais foram criados para que pessoas pudessem estar em contato, independente da localização geográfica de seus interlocutores. Santos (2010) identificou bem esse movimento como cibercultura, dizendo:

A cibercultura é a cultura contemporânea estruturada pelas tecnologias digitais. Não é uma utopia, é o presente; vivemos a cibercultura, seja como autores $e$ atores incluídos no acesso e no uso criativo das tecnologias de informação e comunicação (TICs), seja como excluídos digitais. A exclusão digital é o novo segmento da exclusão social mais amplo. Um desafio político (SANTOS, 2010, p. 29-30).

Nessa perspectiva, progressivamente vimos as transformações que as diferentes mídias sofreram, seja na convergência da própria mídia e da hipermídia ou mesmo no desenvolvimento tecnológico de seu hardware ou software propriamente dito; como exemplo disso tivemos a mudança nas lógicas comunicacionais, de um-todos (rádio, televisão, jornal) para todos-todos (Web); a migração de imagens impressas para o scanner; vídeos filmados com filmadoras de fita migraram para cartões de memória, assim como as músicas dos LPs para os CDs, MP3, MP4; a televisão analógica pra a digital, em que podemos ver a programação dos canais e assistir em qualquer espaçotempo; mais recentemente vimos que muitas hipermídias começaram a interligar informações sobre fatos $e$ acontecimentos em tempo real conectado à internet (um vídeo feito pelo celular e publicado por um usuário da rede sobre algum acontecimento acaba sendo compartilhado por todos na/em rede); todo esse acesso à grande rede (internet) foi possível via conexões discadas, a rádio, cabo ADSL ou $3 G$ cada vez em velocidades mais altas.

As mídias digitais ganharam mobilidade, estabelecendo mudanças irreversíveis na percepção humana devido à diversificação da representação da linguagem, por exemplo, palavras, músicas, fotografias, desenhos, imagens animadas, símbolos, dança, teatro, ou seja, uma verdadeira bricolagem de signos e significados. Importante informar a você, nosso interlocutor, que alguns polos do $\mathrm{Ce}$ derj estavam situados no interior do Estado do Rio de Janeiro, onde as possibilidades de conexão apresentavam-se mais limitadas e instáveis, quando comparadas aos centros urbanos, apesar do acesso às tecnologias digitais mais recentes dentro do mercado brasileiro.

Os alunos precisavam acessar o site da Fundação Cecierj (Figura 2) para estudar na e pela Plataforma Cederj. Para isso, havia a necessidade de ter um dispositivo conectado à internet; entretanto, durante as nossas observações participantes com os praticantes (alunos) e ouvindo e mediando seus relatos, foi possível inferir que a maioria dos discentes não possuía computador em casa e dessa forma buscavam lan houses, desktops do polo, computadores pessoais (PCs) de amigos e parentes para poder acessar o ambiente virtual de aprendizagem (AVA). 


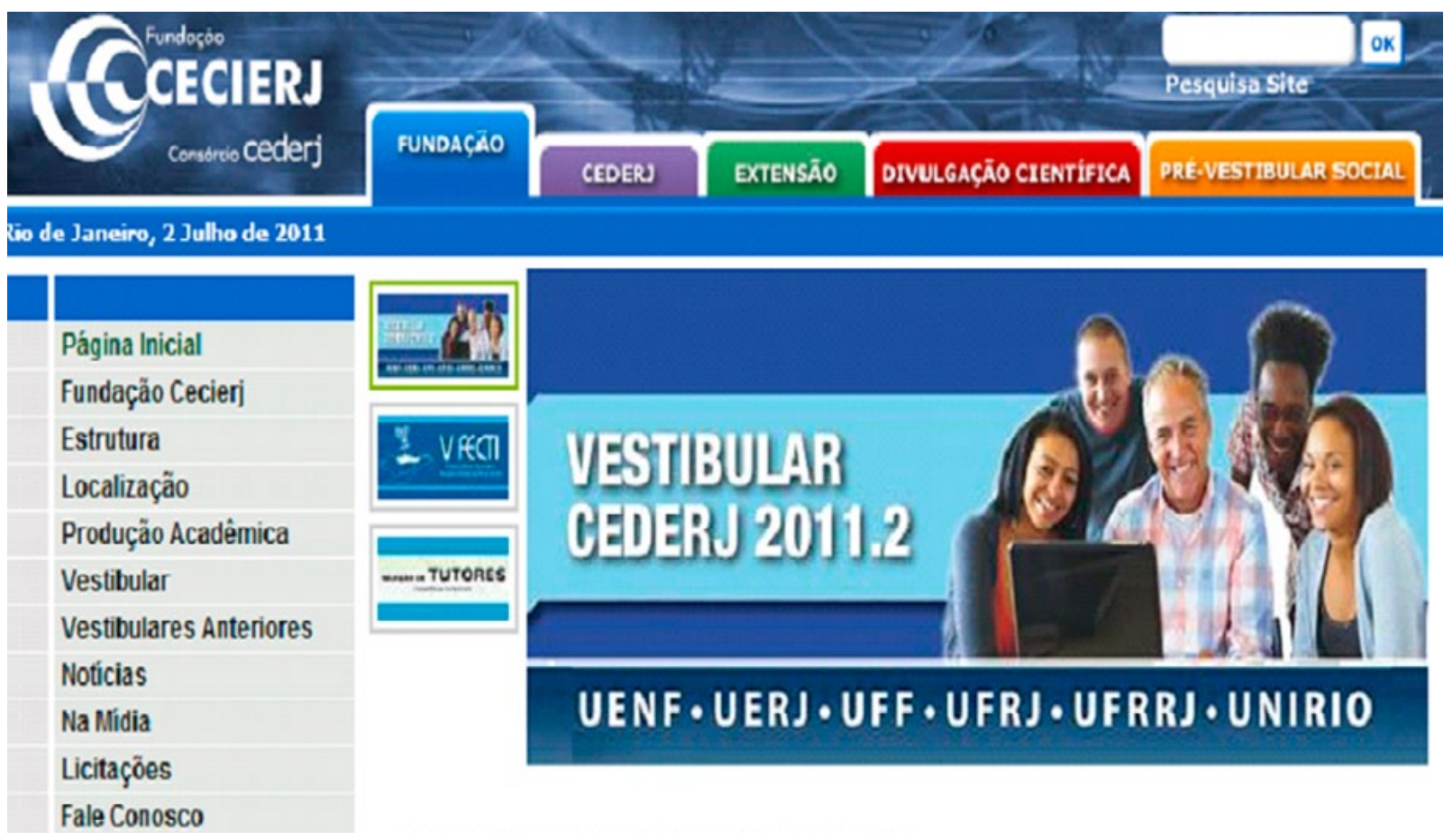

Figura 2: Site da Fundação Cecierj. Disponível em: http://www.cederj.edu.br/fundacao/

A partir da vivência e da tessitura com os alunos, podemos compreender e conhecer melhor quem são esses nossos discentesdocentes que vivenciam a cena sociotécnica hodierna, que utilizam recursos, dispositivos, interfaces dentre outros na/com/da cibercultura e que estudam num curso de graduação a distância que tem como suporte e meio no processo de ensinoaprendizagem a Plataforma Cederj.

A partir dos estudos de Santaella (2004), inferimos que nossos alunos eram leitores do digital ou imersivos, podendo estar no nível novato, leigo ou expert na sua navegação na arquitetura líquida do ciberespaço ${ }^{3}$. Entretanto, para melhor compreender essa interface indivíduo-mídia foi necessário considerar as fases que a antecederam, a partir dos estudos de Santaella (2004):

3 Para Lévy (1999, p. 17), o ciberespaço (que eu também chamarei de "rede") é o novo meio de comunicação que surge da interconexão mundial dos computadores. O termo especifica não apenas a infraestrutura material da comunicação digital, mas também o universo oceânico de informações que ela abriga, assim como os seres humanos que navegam e alimentam esse universo. Quanto ao neologismo "cibercultura", especifica aqui o conjunto de técnicas (materiais e intelectuais), de práticas, de atitudes, de modos de pensamento e de valores que se desenvolvem juntamente com o crescimento do ciberespaço.
Há, assim, o leitor da imagem, no desenho, pintura, gravura, fotografia. Há o leitor do jornal, de revistas. Há o leitor da cidade, leitor da miríade de signos, símbolos e sinais em que se converteu a cidade moderna, a floresta de signos de que falava Baudelaire. Há o leitor-espectador da imagem em movimento, no cinema, televisão e vídeo. A essa multiplicidade mais recentemente vieram se somar o leitor da imagem evanescente da computação gráfica e o leitor do texto escrito, que, do papel, saltou para a superfície das telas eletrônicas. Nessa mesma linha de continuidade, mas em nível de complexidade ainda maior, hoje, esse leitor das telas eletrônicas está transitando pelas infovias das redes, constituindo-se em novo tipo de leitor que navega nas arquiteturas líquidas e alineares da hipermídia do ciberespaço (SANTAELLA, 2004, p. 18).

Dessa forma, compreendemos que uma fase ou uma lógica não foi necessariamente substituída por uma nova que emergiu; elas podem coexistir agregando valor e possibilidades de uso pelo ser humano.

O leitor contemplativo (Figura 3) é aquele leitor do papiro, da pintura, do manuscrito, do livro, que durante os séculos entre o XII e o XVI fazia uma leitura individual, solitária, de foro privado, silenciosa. Há de se considerar que nessa época poucas pessoas tinham acesso ao livro, somente eclesiásticos, as universidades, os jurisconsultos, os conselheiros da monarquia e a rica burguesia, dentre outros que tinham o acesso ao poder. 


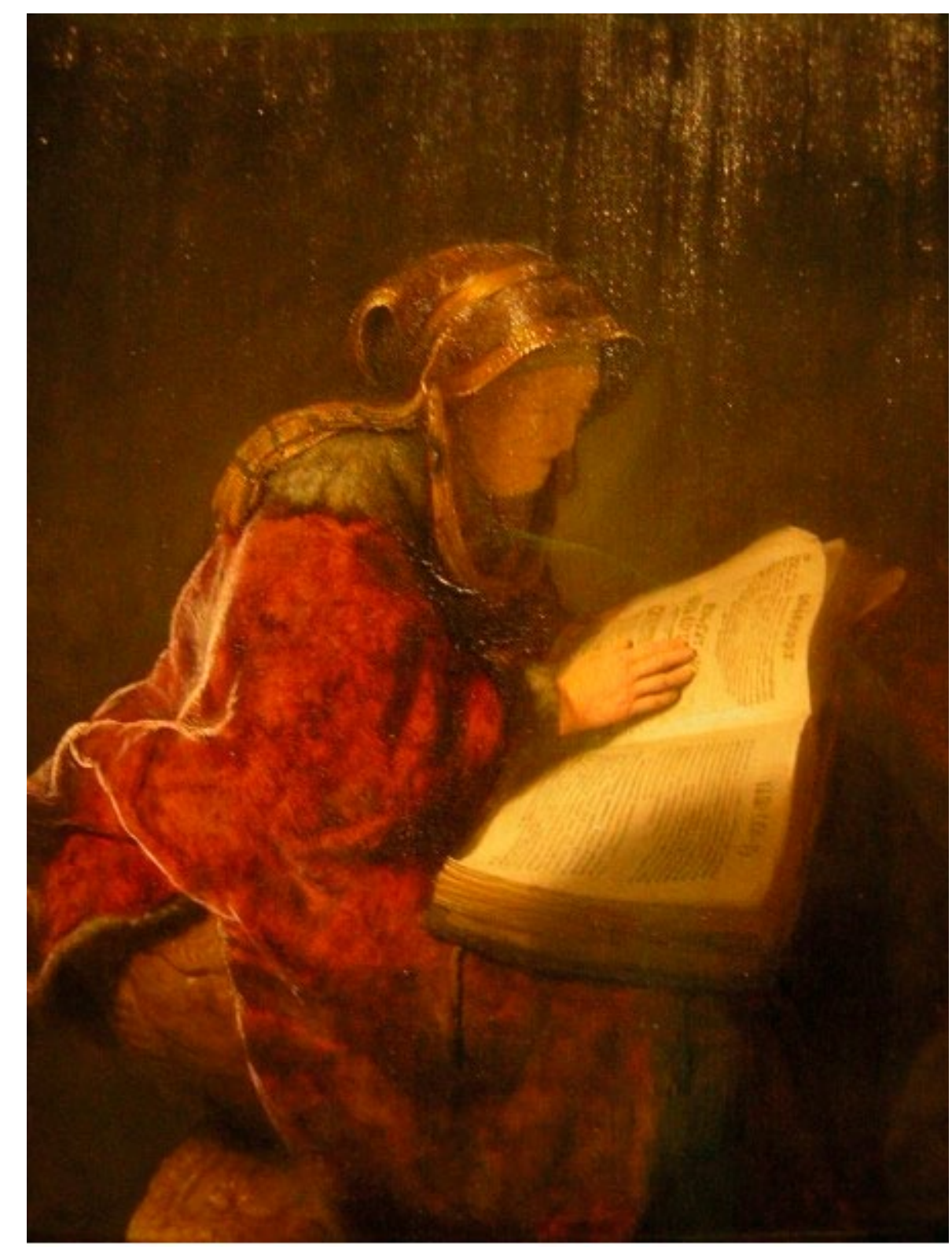

Figura 3: Leitor contemplativo. Disponível em: http://cibelle.arteblog.com.br/238084/O-leitor-contemplativo-meditativo/

No início e durante a Revolução Industrial, houve grande movimento de pessoas saindo em retirada do campo e partindo em direção aos centros urbanos. As cidades, por sua vez, foram sendo reconfiguradas com o avanço das indústrias das máquinas a vapor; estas fizeram a substituição potencializada da força humana e a mecanização da locomoção. Santaella (1997, p. 35) afirma que é justamente esse tipo de funcionamento que esteve na base das primeiras noções de robô, máquina à imagem e semelhança dos músculos humanos, pronta para trabalhar para o homem ou em seu lugar. Nesse período, as cidades co- meçaram a serem invadidas pela iluminação elétrica com seu néon, por lojas de roupas, galerias, parques, cafeterias, cinemas, teatros, museus, boulevards, a moda começou a fazer parte da vida cotidiana com seu consumismo.

Em meio a esse universo fragmentado de imagens, sons, tráfego urbano, multidões de pessoas, consumismo, a sensibilidade do ser humano mudou, pois ele passou a ter mais a consciência do que memória, devido ao abalo da cidade grande na sua vida cotidiana. Nasce, nesse cenário caótico com a chegada do jornal e das multidões nas ruas hiperpovoadas de signos, 
o leitor movente ou fragmentário; é o leitor treinado nas distrações fugazes e sensações evanescentes cuja percepção se tornou uma atividade instável, de intensidades desiguais. É, enfim, o leitor apressado de linguagens efêmeras, híbridas, misturadas (SANTAELLA, 2004, p. 29), que se ajusta à vida moderna e aos novos ritmos de atenção; o tempo agora é escasso, principalmente pelas longas jornadas de trabalho nas fábricas, a cidade em movimento com seus bondes elétricos e suas locomotivas a vapor; o homem moderno não contemplava mais uma leitura, pois ele passou a ser o leitor de jornais, revistas, outdoors, vitrines, letreiros.

Esses dois tipos de leitores (o contemplativo $e$ o movente) foram primordiais para que pudéssemos conhecer melhor o perfil cognitivo do terceiro e último tipo: o leitor imersivo. $\mathrm{O}$ primeiro leitor, aquele contemplativo, leitor de livros, de objetos imóveis, de pinturas, possui semelhança com o imersivo quando diz respeito a utilizar referências, índices e o recorte do texto, porém não em relação ao movente, que faz pressão com os dedos no mouse na barra de rolagem na tela do computador. $\mathrm{O}$ movente ou fragmentário contribuiu com a sensibilidade da percepção humana e que, de fato,

se não levarmos em conta as mudanças na estrutura mesmo da sensomotricidade, na aceleração da percepção, do ritmo da atenção, flutuando entre a distração e a intensidade da penetração no instante perceptivo, trazida pelo leitor movente, fica muito difícil compreender o perfil desse tipo radicalmente novo de leitor (SANTAELLA, 2004, p. 31).

A partir dessas transformações da comunicação verbal e não verbal, em que textos estáticos ganharam mobilidade, versatilidade, outras possibilidades de serem construídos, assim como a oralidade e os caminhos de leitura passaram de uma lógica linear para não linear, dotando o leitor de uma obra de outras possibilidades de interferência tecendo outros caminhos sequer imaginados pelo seu autor. Nesse contexto, formamo-nos e reconhecemos a formação de nossos interlocutores, alunos do Curso de Licenciatura em Pedagogia da UERJ/Fundação
Cecierj que também gradativamente se adaptam ao desenvolvimento das tecnologias digitais.

\section{EaD online e a Educação Online}

De acordo com a Portaria do MEC n ${ }^{\circ} 4.059 / 04$ (BRASIL, 2004), que trata do ensino a distância semipresencial, em seu art. $1^{\circ}$, fica estabelecido que:

\begin{abstract}
as instituições de ensino superior poderão introduzir, na organização pedagógica e curricular de seus cursos superiores reconhecidos, a oferta de disciplinas integrantes do currículo que utilizem modalidade semipresencial, com base no art. 81 da Lei n. 9.394, de 1996, e no disposto nesta Portaria (BRASIL, 2004).
\end{abstract}

Esta configura a modalidade $\mathrm{EaD}$, em seus parágrafos:

\begin{abstract}
$\S 1^{\circ}$ - caracteriza-se a modalidade semipresencial como quaisquer atividades didáticas, módulos ou unidades de ensino-aprendizagem centrados na autoaprendizagem $e$ com a mediação de recursos didáticos organizados em diferentes suportes de informação que utilizem tecnologias de comunicação remota.
\end{abstract}

$\S 2^{\circ}$ - Poderão ser ofertadas as disciplinas referidas no caput, integral ou parcialmente, desde que essa oferta não ultrapasse $20 \%$ (vinte por cento) da carga horária total do curso.

$\S 3^{\circ}$ - As avaliações das disciplinas ofertadas na modalidade referida no caput serão presenciais (BRASIL, 2004).

Essa portaria, também conhecida como "Portaria dos $20 \%$ ", pois garantiu que as instituições de ensino superior pudessem ofertar $20 \%$ das disciplinas regulares presenciais à distância, tendo a internet como suporte. De acordo com o Decreto n ${ }^{\circ} .5 .622 / 05$, Art. $1^{\circ}$,

caracteriza-se a educação a distância como modalidade educacional na qual a mediação didático-pedagógica nos processos de ensino e aprendizagem ocorre com a utilização de meios e tecnologias de informação e comunicação, com estudantes e professores desenvolvendo atividades educativas em lugares ou tempos diversos (BRASIL, 2005). 


\section{Em seu Art. $1^{\circ}$, o $\S 1$ ㅇ do Decreto $n^{\circ} .5 .622 / 05$} (BRASIL, 2005) regulamenta o funcionamento da Educação a Distância desta forma:

será organizada de acordo com as metodologias, gestão e avaliação peculiares, para as quais deverá estar prevista a obrigatoriedade de momentos presenciais para: I -avaliações de estudantes; II - estágios obrigatórios, quando previstos na legislação pertinente; III - defesa de trabalhos de conclusão de curso, quando previstos na legislação pertinente; e IV - atividades relacionadas a laboratórios de ensino, quando for o caso (BRASIL, 2005).

Todavia, torna-se coerente afirmar que a prática pedagógica presente no desenho didático da $\mathrm{EaD}$ online do Cederj é de professores de cursos oferecidos na modalidade presencial e ainda muito influenciados pela concepção da Pedagogia da transmissão, presente nos processos comunicacionais das mídias de massa e trouxeram, ao ambiente online, esse desenho tradicional que pouco explorava as possibilidades de interatividade pelo/com/no AVA. Para Santos (2007),

\begin{abstract}
a EaD é uma modalidade educacional historicamente mediada por mídias de massa (impressos, audiovisuais em geral). Estas, por sua vez, não liberam o polo da emissão. Assim, os aprendentes interagem com o desenho e materiais didáticos sem cocriar, juntamente com seus colegas e professores, o conhecimento. As mídias de massa não permitem interatividade no sentido do mais comunicacional (SILVA, 2000), do cocriar juntos a mensagem. Por conta do limite da mídia de massa a modalidade a distância privilegia pedagogicamente os conceitos de "autoaprendizagem" e "autoestudo". O sujeito interage com o material e aprende por essa mediação. A aprendizagem colaborativa não é vivenciada pelo aprendente. Nesse modelo a qualidade dos processos é centrada no desenho didático ou instrucional, geralmente instrucionista. A interação social, quando acontece, é de um para um, ou seja, professor/ aluno - aluno/professor. O que podemos ter - se o material for bem escrito e desenhado - é a interação com o texto do autor. Interação pode até existir, mas interatividade não tem (SANTOS, 2007).
\end{abstract}

Em contraponto, vivenciamos o estudo da Educação Online como fenômeno da cibercultura. Sobre esse fenômeno, Silva (2008) inferiu que estruturar a prática pedagógica para a Educação Online é antes de qualquer coisa arquitetar um desenho didático como o que envolve o planejamento, a produção e a operatividade de conteúdos e de situações de aprendizagem, que estruturam processos de construção do conhecimento na sala de aula online. Esses conteúdos e situações de aprendizagem devem contemplar o potencial pedagógico, comunicacional e tecnológico do computador online, bem como das disposições de interatividade próprias dos ambientes online de aprendizagem (SILVA, 2008, p. 6).

A compreensão do conceito de interatividade na EaD Online tradicional foi muito influenciada pela perspectiva da Comunicação como área do conhecimento que compreende as possibilidades de interatividade na lógica comunicacional unidirecional (um-todos).

Na perspectiva da Educação Online o conceito de interatividade foi ressignificado a partir dos estudos de Silva (2007) explorando o potencial comunicacional bidirecional (todos-todos) das tecnologias digitais. Contudo, diante da ausência ou pouco desenvolvimento de competências digitais por parte dos professores, observamos a dificuldade do uso do AVA não só em relação ao desenho didático para o trabalho com os conteúdos de cada disciplina, mas principalmente sobre os usos dos softwares e interfaces mais adequados a sua aula. Porém

uma sala de aula online não é apenas o conjunto de ferramentas infotécnicas, mas também um ambiente que se auto-organiza nas relações estabelecidas pelos sujeitos com os objetos técnicos que interagem e afetam-se mutuamente ao longo do processo de construção do conhecimento. Nesse sentido, é preciso que o desenho didático contemple uma intencionalidade pedagógica que garanta a Educação Online como obra aberta, plástica, fluida, hipertextual e interativa. Caso contrário, repetirá práticas próprias da pedagogia da transmissão (SILVA, 2008, p. 6).

\section{Contudo, a Educação Online implica}

investimentos diferenciados em relação à educação presencial e a distância via suportes tradicionais. A primeira exige metodologia própria para educar com base em diálo- 
go, troca, participação, intervenção, autoria, colaboração. É certo que essa metodologia não é prerrogativa do computador conectado, mas é nele que encontra possibilidades de sua potencialização (SILVA, 2003).

O desenho didático da disciplina Informática na Educação representou um momento de intersecção entre a EaD Online, em que o papel do autor, design instrucional e tutoria se materializam na atuação de diferentes sujeitos. É a Educação Online, em que o professor tem as competências e habilidades necessárias para desenvolver conteúdos para ambientes online, além de escolher os softwares e interfaces adequados à sua proposta educacional, mediar e avaliar o processo de ensinoaprendizagem, ou seja,

em lugar de transmitir meramente, o docente online precisará aprender a disponibilizar múltiplas experimentações e expressões, além de montar conexões em rede que permitam múltiplas ocorrências. Em lugar de meramente transmitir, ele será um formulador de problemas, provocador de situações, arquiteto de percursos, mobilizador de experiência do conhecimento. Para isso, contará com ferramentas ou interfaces que compõem o ambiente virtual de aprendizagem (AVA); onde ocorre interatividade há aprendizagem (fórum, chat, blog texto coletivo, portfólio, midiateca e videoconferência no modelo "todos-todos") (SILVA, 2004, 2005, 2006).

O exercício da tutoria presencial na disciplina Informática na Educação representou um momento de coautoria essencial para compreendermos os limites $e$ possibilidades da atuação do professor tanto no desenho tradicional como na docência online.

\section{O desenho didático da disciplina Infor- mática na Educação}

A Educação Online se apresenta diferente da pedagogia da transmissão que é trabalhada no Curso de Licenciatura em Pedagogia UERJ/Fundação Cecierj, apesar de usar as mídias interativas. Pensar Educação Online é pensar em hipertexto, pois no ambiente online, os sites hipertextuais supõem: a) intertextualidade: conexões com outros sites ou documentos; b) intratextualidade: conexões com o mesmo documento; c) multivocalidade: agregar multiplicidade de pontos de vistas; d) navegabilidade: ambiente simples e de fácil acesso e transparência nas informações; e) mixagem: integração de várias linguagens: sons, texto, imagens dinâmicas e estáticas, gráficos, mapas; f) multimídia: integração de vários suportes midiáticos (SANTOS, 2003, p. 225).

Martín-Barbero (1998, apud SILVA, 2009) formula com precisão os desafios específicos do hipertexto para o professor:

\begin{abstract}
O professor terá de dar conta do hipertexto: "Uma escritura não sequencial, uma montagem de conexões em rede que, ao permitir/exigir uma multiplicidade de recorrências, transforma a leitura em escritura." [...] O professor terá de saber que "em lugar de substituir, o hipertexto vem potenciar" sua figura e seu ofício: "De mero transmissor de saberes [o professor] deverá converter-se em formulador de problemas, provocador de interrogações, coordenador de equipes de trabalho, sistematizador de experiências e memória viva de uma educação que, em lugar de aferrar-se ao passado, valoriza e possibilita o diálogo entre culturas e gerações" (...). O professor terá de saber que não se trata de hipostasiar o novo paradigma, mas tomá-lo em recursão com o tradicional, ou seja, terá de saber que de fato há "uma mudança nos protocolos e processos de leitura", mas que o livro de papel, em seu paradigma linear, sequencial, não pode ser invalidado (MARTÍN-BARBERO, 1998, apud SILVA, 2009, p. 42).
\end{abstract}

Diferentemente dessa lógica do mais comunicacional das mídias interativas ou pós-massivas, a $\mathrm{EaD}$ Online praticada no Curso de Licenciatura em Pedagogia UERJ/Fundação Cecierj tem a sua lógica voltada para a lógica comunicacional massiva, em que a aprendizagem está voltada para o autoestudo e a tutoria em sua grande maioria funciona de maneira reativa, em que as dúvidas devem surgir da leitura dos alunos exclusivamente, não havendo relação dialógica e sim de pergunta e resposta.

Sobre a itinerância de avanços na formação de professores tutores presenciais que efetivamente pesquisam a sua própria prática docente cocriando etnométodos em relação ao fazer pedagógico, Santos (2007) diz: 
O pesquisador não é aquele quem constata o que ocorre, mas também aquele que intervém como sujeito de ocorrências. Ser sujeito de ocorrências no contexto de pesquisa e prática pedagógica implica conceber a pesquisa-formação como processo de produção de conhecimentos sobre problemas vividos pelo sujeito em sua ação docente. (...) A pesquisa-formação não dicotomiza a ação de conhecer da ação de atuar. (...) O pesquisador é coletivo, não se limita a aplicar saberes existentes, as estratégias de aprendizagem e os saberes emergem da troca e da partilha de sentidos de todos envolvidos (SANTOS, 2007, p. 13-14).

A princípio, o que podemos verificar em relação à utilização da Plataforma Cederj, em relação à construção do conhecimento de forma geral nas disciplinas, foi que esse AVA até então era utilizado como repositório, só servindo para que os professores disponibilizassem as aulas em formato pdf $e$ as avaliações a distância (ADs) e presenciais (APs) para que os alunos pudessem baixar (download), desenvolver as questões propostas e entregassem suas avaliações manuscritas ou impressas na secretaria do polo; essa entrega acontecia presencialmente ou pelo envio da AD por Sedex. Nesta última opção, o prazo era subtraído em uma semana visando garantir o recebimento no polo dentro do prazo final. As avaliações podiam ser mediadas ou não pela tutoria presencial, caso houvesse tutor presencial para a disciplina cursada; em caso de dúvida, o aluno poderia entrar em contato pelo telefone 0800 ou e-mail com a tutoria a distância. Essa prática sugeria o autoestudo presente também nos cursos EaD tradicionais, sem a possibilidade do ciberespaço.

Na perspectiva da Educação Online, em que a avaliação formativa implica o "investimento em atividades e dispositivos que permitam reflexão e comunicação interativa" (SANTOS, 2006, p. 317), o processo de ensinoaprendizagem ocorreu numa relação dialógica desde o início da disciplina, no desenvolvimento de cada atividade proposta como $\mathrm{AD}$ e AP, avançando no uso da interface do AVA Cederj com mediações que ocorreram dentro do AVA, no presencial e em sites e blogs ditos educativos por seus autores, estes últimos como AVAs abertos.
Nesse sentido, gradativamente cooperamos $e$ colaboramos para ressignificar o processo de ensinoaprendizagem no Curso de Pedagogia UERJ/Fundação Cecierj em busca de criar possibilidades aos seguintes questionamentos: como criar situações de aprendizagem a partir da interface do AVA Cederj? Qual metodologia daria conta de justificar uma aprendizagem autônoma para os atores envolvidos na disciplina Informática na Educação?

Em Santos e Riccio (2011) compreendemos a ressignificação do termo autonomia em espaçotempos de cibercultura quando afirmam:

\begin{abstract}
Ao contrário, a autonomia aqui é entendida, com base nas concepções de Castoriadis (2000) e Freire (2006), como uma troca com o outro, numa busca coletiva de assunção de si mesmo como autor e como sujeito crítico capaz não só de compreender o mundo mas também de transformá-lo, visando também à autoria do outro, num processo de retroalimentação constante e sem fim, de colaborações e autorias (SANTOS; RICCIO, 2011, p. 1).
\end{abstract}

Podemos inferir que outro desenho didático no Curso de Pedagogia UERJ/Fundação Cecierj foi se formando a partir das responsabilidades assumidas durante o processo de construção do conhecimento, de mobilização de competências, enfim do reconhecimento da autoria e coautoria de cada ator, estudantes e formadores, reconhecidos pela autora da disciplina, professora Edméa Santos ${ }^{4}$, como sujeitos de ocorrências a partir de seus papéis específicos e complementares.

No primeiro fórum proposto na disciplina, começamos a construir o perfil de cada sujeito de ocorrência de acordo com a mediação $e$ intervenção de cada um ao tecer suas histórias e expectativas.

De posse da intenção de uma leitura imersiva e ciente da origem de leitores contemplativos e/ou moventes, o exercício da tutoria presencial consistia em subsidiar de diferentes formas os encontros presenciais ou no AVA, com inquietações que provocassem outro envolvimento dos alunos tão habituados ao

4 http://docenciaonline.pro.br/moodle/course/view.php?id=2 
autoaprendizado. A necessidade de ler e reler ${ }^{5}$ os hiperdocumentos habilitou cada interlocutor à faculdade de intervir com questionamentos mais autorais.

$\mathrm{O}$ desafio de interagir em infovias até então desconhecidas ou pouco conhecidas mobilizou maior necessidade de orientações de navegabilidade nos sites/ softwares sociais. A proposta de navegar por sites educativos, com levantamento de indicadores essenciais da proposta de um dispositivo educacional, possibilitou a produção de novos conhecimentos sobre o uso do ciberespaço com a intencionalidade do educador, reconhecendo-os como professores e pais em alguns casos.

A mobilização de competências para a construção de blogs educacionais trouxe outro momento no processo da avaliação formativa, no que tange ao trabalho realizado em sala de aula na modalidade de ensino presencial, por aqueles que viviam suas primeiras experiências pelo motivo do estágio supervisionado ou por quem já exercia o magistério no Ensino Fundamental.

Podemos avaliar que nesse processo de publicação das autorias dos alunos nos blogs, o desconforto percorreu questões como "O que eu devo/posso publicar?", "O que eu sei para socializar?", "Como eu posso publicar?". Enfim, cada sujeito de ocorrências assumiu sua intencionalidade, suas limitações e enfrentamentos perante essas construções de novos conhecimentos. Esse processo ocorreu nas trocas presenciais e online $e^{6}$, com a utilização da interface comunicacional assíncrona; com algumas turmas foi possível utilizar o chat do AVA Cederj como interface comunicacional síncrona, de acordo com a viabilidade técnica e operacional da Plataforma Cederj e com a qualidade de conexão com a Internet. Há pertinência em reconhecer esses momentos de desconforto do apren-

5 A possibilidade de leitura ou releitura neste trabalho deve ser entendida para além da leitura de um texto, considerando os links (ligações) com outras mídias como vídeo, imagens, textos, sites, softwares etc. que configuram os hiperdocumentos da disciplina Informática na Educação.

6 Na perspectiva da Educação Online, o termo online implica mediações presenciais e no ciberespaço, pois os sujeitos off line são afetados pelas informações e conhecimentos que circulam e são construídos por residentes do ciberespaço. dente como inquietações e vivência de processos de desequilíbrio/equilíbrio/desequilíbrio (PIAGET, 1990).

Construir e habitar situações de aprendizagem online significou investir na criação de outras "interfaces (zona de desenvolvimento proximal - ZDP) entre o real e o potencial em que procuramos atuar pedagógica e, sobretudo, intencionalmente, pois o que é em um momento ZDP em outro é real" (VYGOSTKY, 1993, 1994).

\section{Considerações finais}

Ao tecer essa reflexão sobre o desenho didático das disciplinas do Curso de Licenciatura em Pedagogia UERJ/Fundação Cecierj, foi possível construir outras possibilidades de intervenção no processo de ensinoaprendizagem respeitando os limites da EaD Online institucional e experimentar situações de aprendizagem motivadas pela perspectiva da Educação Online, ou seja, a docência online na disciplina Informática na Educação permitiu navegar melhor e compreender o potencial comunicacional e educacional da Plataforma Cederj, em que a imersão não ocorre de forma intuitiva, devido ao desenvolvimento técnico alcançado nesta e por esta até o momento em que se deu a nossa tutoria.

O desenho didático de materiais impressos da EaD Online deve ser considerado, principalmente em cursos tradicionalmente influenciados pelas metodologias do ensino presencial, como vimos nas disciplinas do Curso de Pedagogia UERJ/Fundação Cecierj, porém neste trabalho restringimo-nos ao desenho didático que ocorreu no sistema de tutoria presencial, tendo sua possibilidade de coautoria a partir das interfaces comunicacionais síncronas $e$ assíncronas com os sujeitos de ocorrências dela $e$ respeitando os limites praticados na parceria UERJ/ Fundação Cecierj. 


\section{Referências}

ALVES, Nilda. Sobre as razões das pesquisas nos/dos/com os cotidianos. Disponível em: < $\underline{\mathrm{http}} / / \mathrm{www}$. grupalfa.com.br/arquivos/Congresso trabalhosII/palestras/Nilda.pdf >. Acesso em: 15 fev. 2011.

BARBIER, René. A pesquisa-ação. Brasília: Liber Livro, 2007 [Trad. Lucie Didio].

BRASIL. Ministério da Educação. Decreto no 5622. Brasília, dez. 2005. Disponível em: <http://www.planalto. gov.br/ccivil 03/Ato2004-2006/2005/Decreto/D5622.htm>. Acesso em: 22 mar. 2011.

. Ministério da Educação. Portaria no 4.059. Brasília, dez. 2004. Disponível em: < $\underline{n^{\circ} 4.059 / 2004}$ >. Acesso em: 22 mar. 2011.

. Ministério da Educação. Plano Nacional de Educação. Disponível em: < http://portal.mec.gov.br/ arquivos/pdf/pne.pdf > . Acesso em: 23 abr. 2011.

CERTEAU, M. A invenção do cotidiano: artes de fazer. Petrópolis: Vozes, 2004.

CUNHA, Paulo; LEMOS, André (orgs.). Olhares sobre a cibercultura. Porto Alegre: Sulina, 2003.

FREIRE, Paulo. Pedagogia da autonomia. Ano da digitalização: 2002. Disponível em: <www.sabotageem. revolt.org >. Acesso em: 03 abr. 2011.

FREITAS, Maria Tereza. Cibercultura e formação de professores. Belo Horizonte: Autêntica, 2009 (Coleção Leitura, Escrita e Oralidade).

INSTITUTO NACIONAL DE ESTUDOS E PESQUISAS EDUCACIONAIS ANÍSIO TEIXEIRA (INEP). Sinopses

Estatísticas da Educação Superior - Graduação. Disponível em: <http://www.inep.gov.br/superior/ censosuperior/sinopse/default.asp>. Acesso em: 23 abr. 2011.

LÉVY, Pierre. A inteligência coletiva: por uma antropologia do ciberespaço. São Paulo: Loyola, 1998.

Cibercultura. São Paulo: Ed. 34, 1999 [Trad. Carlos Irineu da Costa] (Coleção Trans).

LIMA, Rosângela Lopes. Tutoria do Cederj - Capacitação de Profissionais Comprometidos com o Aprendizado do Aluno. Universidade Federal Fluminense/Cederj. 2002. Disponível em: < http://docs.google.com/viewer?a=v \&q=cache:m8eHFm69a6YJ:www.ic.uff.br. Acesso em: 23 abr. 2011.

OKADA, Alexandra; OKADA, Saburo; SANTOS, Edméa. Colearn: ciberconferência e cibermapeamento para aprendizagem colaborativa aberta em cibercomunidades. II Simpósio Nacional ABCIBER 2008. Associação

Brasileira de Pesquisadores em Cibercultura. Disponível em: http://cencib.org/simposioabciber/PDFs/CC/ Alexandra\%20Okada,\%20Saburo\%20Okada\%20e\%20Edmea\%20Santos.pdf>. Acesso em: 24 abr. 2011.

PIAGET, Jean. A formação do símbolo na criança: imitação, jogo e sonho, imitação e representação. Rio de Janeiro: LTC, 1990.

SANTAELLA, Lucia. Navegar no ciberespaço: o perfil do leitor imersivo. São Paulo: Paulus, 2004 (Comunicação).

SANTOS, Edméa O. Articulação de saberes na EaD online: por uma rede interdisciplinar e interativa de conhecimentos em ambientes virtuais de aprendizagem. In: SILVA, Marco (org.). Educação Online. São Paulo: Loyola, 2003. 
. Portifólio e cartografia cognitiva: dispositivos e interfaces para a prática da avaliação formativa em educação online. In: SILVA, M.; SANTOS, E. (orgs.). Avaliação da aprendizagem em educação online. Fundamentos, interfaces e dispositivos, relatos de experiências. São Paulo: Loyola, 2006.

SANTOS, Edméa; RICCIO, Nicia Cristina R. Desenho didático aberto: uma experiência de Educação Online na formação do docente superior na UFBA. E-book: BARROS, D. M. V. et al.. Educação e tecnologias: reflexão, inovação e práticas. Lisboa: [s.n.], 2011. ISBN: 978-989-20-2329-8-1. Disponível em: <http://www.scribd.com/ full/49394657?access_key=key-ah2rll3aldrl5hg4ifk>. Acesso em: 21 abr. 2011.

SILVA, Marco (coord.). Desenho didático em Educação Online. Anais do XIV ENDIPE (Encontro Nacional de Didática e Prática do Ensino): Trajetórias e processos de ensinar e aprender - lugares, memórias e culturas. Porto Alegre: PUC/RS, 27 a 30 de abril de 2008.

SILVA, Marco. Formação de professores para a docência online. Actas do X Congresso Internacional Galego-Português de Psicopedagogia. Braga: Universidade do Minho, 2009. ISBN-978-972-8746-71-1. Disponível em: <http://www.educacion.udc.es/grupos/gipdae/congreso/Xcongreso/pdfs/cc/cc2.pdf > . Acesso em: 24 abr. 2011.

Sala de aula interativa. $4^{\mathrm{a}}$ ed. Rio de Janeiro: Quartet, 2006.

SILVA, Marco; PESCE, Lucila; ZUIN, Antonio (orgs.). Educação Online. Cenário, formação e questões didático-metodológicas. Rio de Janeiro: Wak, 2010.

VYGOTSKY, L. S. A formação social da mente. São Paulo: Martins Fontes, [1930] 1994.

. Pensamento e linguagem. São Paulo: Martins Fontes, [1934] 1993. 